\title{
MARCAÇÃO IMUNOISTOQUÍMICA DA EXPRESSÃO ASTROCITÁRIA DE PROTEÍNA GLIAL FIBRILAR ÁCIDA E DE VIMENTINA NO SISTEMA NERVOSO CENTRAL DE CÃES COM CINOMOSE
}

\author{
Heloísa Orsini', Eduardo Fernandes Bondan², Melissa Sanchez 3 , Maria Anete Lallo4, \\ Paulo César Maiorka5 , Maria Lúcia Zaidan Dagli', Dominguita Luthers Graça7
}

\begin{abstract}
RESUMO - Uma vez que muitos dos aspectos envolvidos na patogenia dos processos desmielinizantes do sistema nervoso central (SNC) são ainda pouco esclarecidos e que os astrócitos parecem estar envolvidos na mediação de tais processos, este estudo analisou morfologicamente a participação astrocitária na desmielinização do SNC por meio da marcação imunoistoquímica de duas proteínas dos filamentos intermediários astrocitários - a proteína glial fibrilar ácida (GFAP) e a vimentina (VIM) -, comparando amostras de cerebelo e de tronco encefálico de oito cães com cinomose e de dois cães normais, de diferentes raças e com idades entre um e quatro anos. Cortes histológicos dos tecidos foram submetidos à marcação pelo método indireto da avidina-biotina-peroxidase $(A B C)$ e a reatividade astrocitária, observada em microscopia de luz, foi quantificada em um sistema computacional de análise de imagens. Observou-se, na maioria dos cortes de animais doentes, a presença de lesões degenerativas compatíveis com desmielinização. A marcação para a GFAP e para a VIM foi mais intensa nos animais com cinomose do que nos animais normais, especialmente nas regiões circunventriculares e nas adjacentes às áreas de degeneração tecidual. Não houve diferença significativa entre a imunomarcação (GFAP e VIM) dos animais com cinomose com e sem infiltração inflamatória da substância branca do cerebelo. O aumento da imunorreatividade dos astrócitos para a GFAP e a reexpressão de VIM nas áreas lesionais indicam o envolvimento astrocitário na resposta do tecido nervoso às lesões desmielinizantes induzidas pelo vírus da cinomose (CDV) no SNC.
\end{abstract}

PALAVRAS-CHAVE: astrócitos, desmielinização do SNC, cinomose canina, GFAP, vimentina.

Immunohistochemical staining of the astrocytic expression of glial fibrillary acidic protein and vimentin in the central nervous system of dogs with canine distemper.

\begin{abstract}
Considering that many aspects involved in the pathogenesis of the central nervous system (CNS) demyelinating diseases are still poorly understood and that astrocytes seem to mediate such processes, this study analyzed the participation of astrocytes in the demyelinating processes of CNS by using immunohistochemical staining of two astrocytic proteins - glial fibrillary acidic protein (GFAP) and vimentin (VIM) -, comparing samples of cerebellum and brainstem from eight dogs with canine distemper and from two healthy dogs, from different breeds and ages varying from 1 to 4 years old. Histological sections were submitted to the avidin-biotin-peroxidase indirect method of immmunohistochemical staining $(A B C)$ and the astrocytic reactivity, observed in light microscopy, was quantified in a computer system for image analysis. It was possible to notice, on most of the sections from sick animals, degenerative lesions that indicate demyelination. The immunostaining for GFAP and VIM was more intense on animals with canine distemper, specially around the ventricules and near degenerated sites. There was no significant difference between the immunostaining (GFAP and VIM) of animals with canine distemper with and without inflammatory infiltrate of the cerebellar white matter. The increased immunoreactivity of astrocytes for GFAP and the VIM reexpression in injured areas indicate the astrocytic involvement on nervous tissue response to the demyelinating lesions induced by the canine distemper virus (CDV) in the CNS.
\end{abstract}

KEY WORDS: astrocytes, CNS demyelination, canine distemper, GFAP, vimentin.

\footnotetext{
'Mestranda em Medicina Veterinária na Universidade Paulista (2005-2006), Professora Auxiliar da Universidade Cruzeiro do Sul, São Paulo SP, Brasil (UNICSUL); ${ }^{2}$ Professor Titular da Universidade Paulista, São Paulo SP, Brasil (UNIP) e da UNICSUL; ${ }^{3}$ Professora Auxiliar da UNIP e da UNICSUL; ${ }^{4}$ Professora Titular da UNIP e da UNICSUL; ${ }^{5 P r o f e s s o r ~ A s s i s t e n t e, ~ D e p a r t a m e n t o ~ d e ~ P a t o l o g i a ~ A n i m a l ~ d a ~ F a-~}$ culdade de Medicina Veterinária da Universidade de São Paulo, São Paulo SP, Brasil (FMVZ/USP); ${ }^{6}$ Professora Titular, Departamento de Patologia Animal da FMVZ/USP; ${ }^{7}$ Professora Titular, Departamento de Patologia da Universidade Federal de Santa Maria, Santa Maria RS, Brasil (UFSM). Apoio Financeiro: Coordenação de Aperfeiçoamento de Pessoal de Nível Superior (CAPES).
}

Recebido 15 Fevereiro 2007, recebido na forma final 29 Maio 2007. Aceito 30 Julho 2007.

Dra. Heloísa Orsini de Souza - Avenida Clavásio Alves da Silva 820 / ed. 3 / apto 154 - 02722-030 São Paulo SP - Brasil. E-mail: helorsini@ yahoo.com.br 
Diversos eventos patológicos possuem como efeito final a desmielinização do sistema nervoso central (SNC) $)^{1,2}$. Muitos dos fatores envolvidos nos processos de perda e de reparo mielínico, no entanto, são ainda pouco esclarecidos ${ }^{3-6}$. Na tentativa de elucidar os eventos celulares envolvidos nos processos de desmielinização e de remielinização do SNC e de buscar estratégias terapêuticas que solucionem ou previnam os danos gerados, têm sido desenvolvidos estudos empregando modelos experimentais de desmielinização', e a cinomose - grave doença viral de cães e outros carnívoros ${ }^{45,7}$ - pode ser considerada como um importante modelo para auxílio no esclarecimento de tais questões ${ }^{3-6}$. As lesões desmielinizantes causadas pelo vírus da cinomose (CDV) no SNC se assemelham, em muitos aspectos, às geradas em doenças desmielinizantes humanas, tais como a esclerose múltipla ${ }^{4,5,8}$ e a panencefalite esclerosante subaguda ${ }^{9}$. Nos estudos dos mecanismos envolvidos nos processos de desmielinização e de remielinização do SNC diversos tipos celulares têm sido avaliados. Alguns desses estudos revelaram que, apesar da existência de infecção de oligodendrócitos pelo CDV, evidências de replicação viral não são encontradas nessas células, descartando a possibilidade de a desmielinização ser gerada por ação direta dos vírus neste tipo celular ${ }^{6,10}$. O acometimento neuronal pelo CDV também é muito pequeno para desencadear a perda maciça de mielina observada nas lesões desmielinizantes ${ }^{11}$. A participação de células inflamatórias é sugerida por outros autores como causa de desmielinização; entretanto, tais células encontram-se presentes apenas na fase crônica das doenças desmielinizantes ${ }^{3,8,12,13}$. Assim, a desmielinização aguda deve estar relacionada à ação de outros tipos celulares, tais como a micróglia ${ }^{14,15}$ e os astrócitos ${ }^{6,10,14}$.

Os astrócitos, componentes da macróglia e responsáveis por diferentes funções de controle da homeostasia no interior do $\mathrm{SNC}^{6,16-18}$, são sugeridos como mediadores dos processos de desmielinização do tecido nervoso, visto que respondem prontamente a uma ampla variedade de estímulos agressores ${ }^{7,16,18,19} \mathrm{e}$ desempenham funções imunológicas ${ }^{3}$, como, por exemplo, fagocitose, apresentação de antígenos ${ }^{12,14,18,20,21}$ e liberação de fatores tóxicos e citocinas pró-inflamatórias e antiinflamatórias ${ }^{10,16,18,21}$. A reatividade astrocitária se manifesta com proliferação (astrocitose) e hipertrofia (astrogliose) 7,18, expressando-se com aumento na quantidade de filamentos intermediários e de suas proteínas constituintes, tais como a proteína glial fibrilar ácida (GFAP) e a vimentina (VIM), contidas no citoplasma celular ${ }^{16,22,23}$. A GFAP é o principal componente estrutural dos astrócitos de indivíduos adultos e a VIM é predominante no período embrionário, sendo perdida conforme ocorre o amadurecimento celularir,18,23,24. Nas lesões do SNC, é comum a expressão de GFAP tornar-se muito intensa ${ }^{7,25-28}$, e a VIM, antes perdida, ser reexpressa $a^{23,25,28}$.

Este estudo teve como objetivo investigar a resposta morfológica e a distribuição dos astrócitos frente ao processo desmielinizante do SNC na cinomose canina, por meio da marcação imunoistoquímica da reatividade da GFAP e da VIM, com o intuito de inferir aspectos relativos ao comportamento destas células na patogenia da desmielinização do SNC.

\section{MÉTODO}

Com a intenção de avaliar a desmielinização gerada em processos naturais, não induzidos experimentalmente, este trabalho utilizou material proveniente de arquivos de necropsia. Amostras de cerebelo e de tronco encefálico de cães que vieram a óbito com diagnóstico histopatológico de cinomose e de cães clinicamente normais (sem lesões observáveis no SNC) foram analisadas neste estudo; entretanto, somente amostras que se adequavam a critérios de preservação antigênica e tecidual previamente determinados foram selecionadas. Foram examinadas apenas amostras recentes, que não permaneceram por mais de uma semana no método de fixação, e provenientes de animais que apresentavam características histológicas semelhantes na análise do material em microscopia de luz - no caso dos animais doentes, amostras com vacuolização tecidual e algum nível de infiltração inflamatória perivascular, ou seja, de animais que morreram na fase crônica da desmielinização. Foram utilizadas neste estudo oito amostras de cerebelo e cinco de tronco encefálico de oito cães com cinomose, de diferentes raças e idade entre um e quatro anos, e duas amostras de dois cães clinicamente normais, com as mesmas características de raça e idade. As amostras, previamente fixadas em formol tamponado a $10 \%$ e incluídas em parafina, foram submetidas à marcação imunoistoquímica da GFAP e da VIM, pelo método indireto do complexo avidina-biotina-peroxidase ( $A B C$ ). Cortes histológicos (de $5 \mu \mathrm{m}$ de espessura) foram submetidos à coloração por hematoxilina e eosina $(\mathrm{HE})$, servindo como controle histopatológico. Para a marcação imunoistoquímica da GFAP e da VIM, cortes histológicos das amostras foram coletados em lâminas silanizadas (Stairfrost ${ }^{\circledR}$-Objektträger, Medite Medizintechnik).

A marcação das proteínas gliais seguiu o método utilizado por Bondan et al. ${ }^{25}$ e Sanchez et al. ${ }^{28}$ nos seus estudos com ratos Wistar. Os cortes colhidos em lâminas silanizadas foram desparafinados em xilol e hidratados em uma seqüência decrescente de etanóis. Foram, então, incubados durante 24 horas, a $4^{\circ} \mathrm{C}$, com o anticorpo primário policlonal anti-GFAP (Rabbit anti-cow GFAP, code number ZO334, DAKO) ou com o anticorpo monoclonal anti-VIM (Mouse anti-swine VIM, code number $\mathrm{MO}_{725}$, DAKO), padronizados, respectivamente, nas diluições 1:1000 e 1:200. Posteriormente, foram incubados por uma hora com o anticorpo secundário biotinilado anti-imunoglobulinas de coelho e anti-imunoglobulinas de camundongo (Novostain Super 
ABC Kit, Novocastra), na diluição 1:100 e, após, com o conjugado estreptavidina-biotina-peroxidase (Novostain Super $A B C$ Kit, Novocastra) por mais uma hora. A imunorreatividade foi visualizada pela aplicação sobre os cortes de diaminobenzidina (DAB, Sigma) a 0,1\% como cromógeno e peróxido de hidrogênio a $0,5 \%$. Os cortes foram contracorados com hematoxilina, desidratados, diafanizados e montados com resina sintética sob lamínula. Todas as reações foram acompanhadas por lâminas de controle negativo, submetidas a todas as etapas do procedimento, exceto à aplicação do anticorpo primário.

Áreas de $302.952,5 \mu \mathrm{m}^{2}$ dos cortes submetidos à prova imunoistoquímica foram analisadas em microscopia de luz (com objetiva de 10X), para avaliação da imunorreatividade das células marcadas para a GFAP ou para a VIM (coradas em castanho). Foram tomadas medidas de cada uma das três regiões cerebelares selecionadas, seguindo o critério utilizado por Headley et al. ${ }^{26}$ : R-1 (constituída pela substância branca abaixo das folias cerebelares), R-2 (composta pela base das folias, contendo, além da substância branca, as camadas granular e molecular) e R-3 (contendo as mesmas estruturas de R-2, mas obtida da extremidade distal das folias cerebelares). A imunorreatividade das proteínas gliais também foi avaliada na substância branca do cerebelo dos animais doentes nas condições de presença e ausência de infiltração inflamatória perivascular e nas condições de presença e ausência de degeneração tecidual. Do tronco encefálico, medidas dos animais normais e dos animais com cinomose foram tomadas de duas regiões selecionadas: uma imediatamente abaixo do epêndima (r-I) e outra mais ventral (r-II). Comparações intergrupos e intragrupo foram estabelecidas.

A reatividade astrocitária foi determinada por colorimetria em um sistema computacional de análise de imagens, o Image-Pro Plus 4.5 (Media Cybernetics, Silver Spring, EUA), quantificando, em $\mu \mathrm{m}^{2}$, a área marcada em castanho contida na área total de $302.952,5 \mu \mathrm{m}^{2}$. Os resultados numéricos obtidos no software foram submetidos à análise estatística pelos métodos não-paramétricos de Mann-Whitney e Kruskal-Wallis, utilizando-se a mediana como estimador da medida de posição e o intervalo interquartil (diferença entre os valores dos percentis 75 e 25) como estimador da medida de dispersão. A significância estatística para todas as provas foi aceita em $\alpha \leq 0,05$.
Este estudo foi avaliado e aprovado pelo Comitê de Ética em Pesquisa da Universidade Paulista (UNIP) - São Paulo, 2005 .

\section{RESULTADOS}

Observou-se, na análise histopatológica dos cortes corados por HE dos animais com cinomose, a presença de degeneração (caracterizada por microcavitações teciduais) em todas as amostras, variando em intensidade e extensão (Fig $1 \mathrm{~A}$ ). Lesões degenerativas mais intensas foram encontradas na substância branca e nas regiões circunventriculares do cerebelo e do tronco encefálico. A infiltração de células inflamatórias (linfócitos e monócitos) foi observada em todos os cortes, especialmente nas regiões perivasculares da substância branca (Fig 1B); entretanto, apresentaram variações no número de camadas de células inflamatórias que compunham os manguitos. Corpúsculos de inclusão eosinofílicos intranucleares foram encontrados em astrócitos. Nas amostras obtidas de animais normais, não foram observadas quaisquer alterações estruturais ou celulares no tecido nem a presença de infiltrados inflamatórios.

$\mathrm{Na}$ análise da marcação para a GFAP, os cortes provenientes de animais com cinomose apresentaram células positivas para a proteína distribuídas de forma difusa por toda a extensão do tecido, especialmente na substância branca, nas áreas circunventriculares do cerebelo e do tronco encefálico e nas proximidades das áreas com degeneração. Dentre as regiões selecionadas para a quantificação computacional, R-1 do cerebelo (composta apenas pela substância branca) e r-I do tronco encefálico (constituída pela região imediatamente abaixo do epêndima) obtiveram marcação mais intensa. A imunorreatividade astrocitária foi maior no grupo de animais doentes do que no de animais normais (Fig $2 \mathrm{~A}$ e $2 \mathrm{~B}$ ). As células marcadas para a GFAP nos animais com cinomose apre-

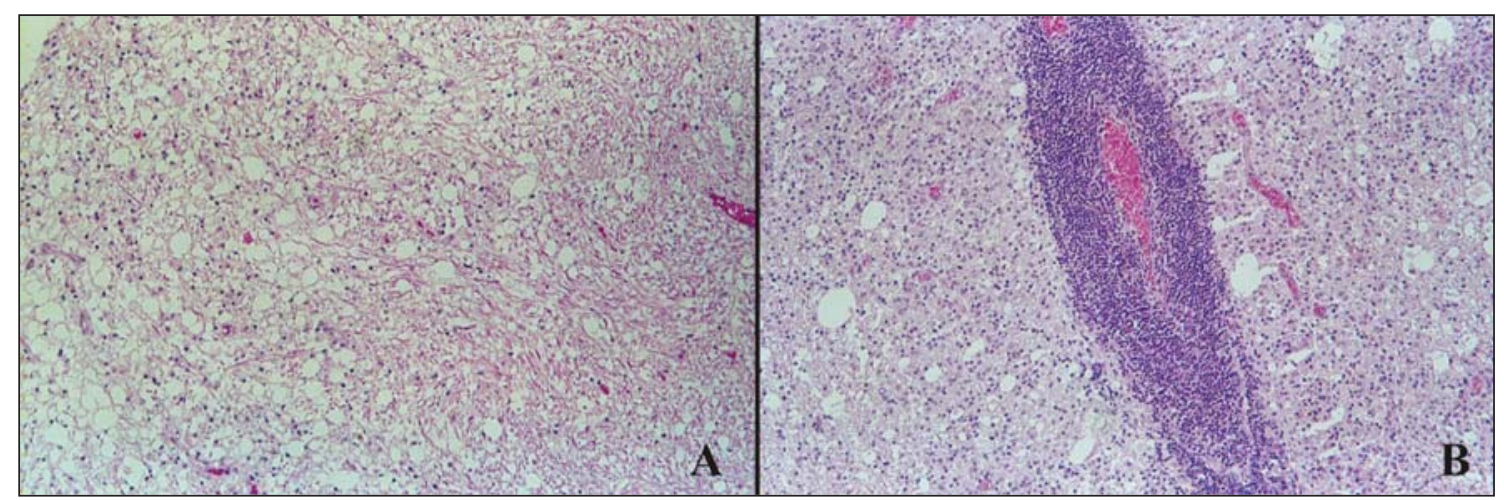

Fig 1. A) Microcavitações teciduais compatíveis com desmielinização na substância branca do cerebelo de um cão com cinomose. Obj. 10x. B) Infiltração inflamatória perivascular no SNC de um cão com cinomose. Obj. 10x. 


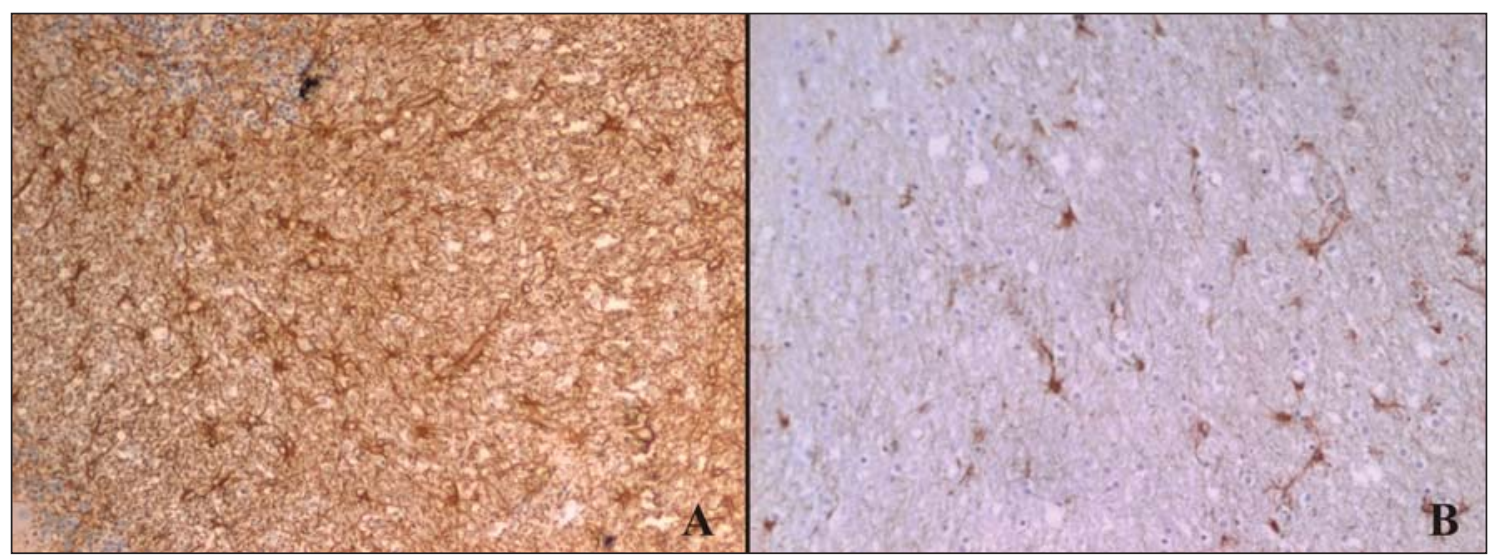

Fig 2. Marcação imunoistoquímica da GFAP na substância branca do cerebelo de animais com cinomose (A) e de animais normais (B). Obj. 10x.

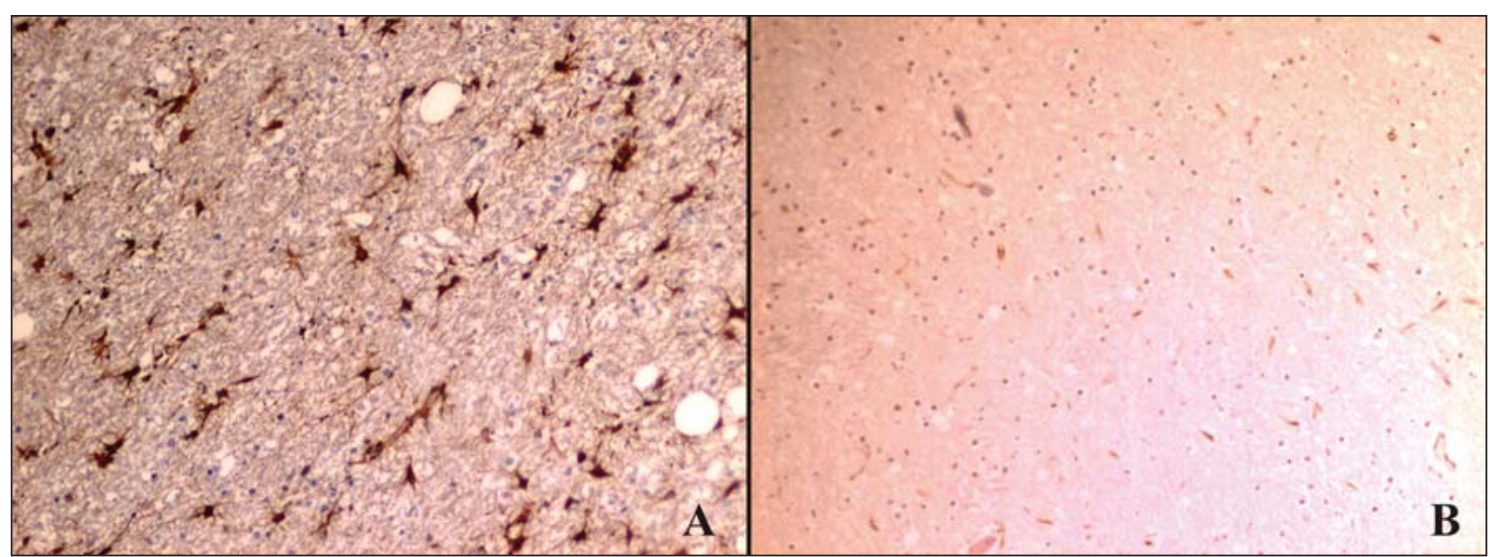

Fig 3. Marcação imunoistoquímica da VIM na substância branca do cerebelo de animais com cinomose (A) e de animais normais (B). Obj. $10 x$.

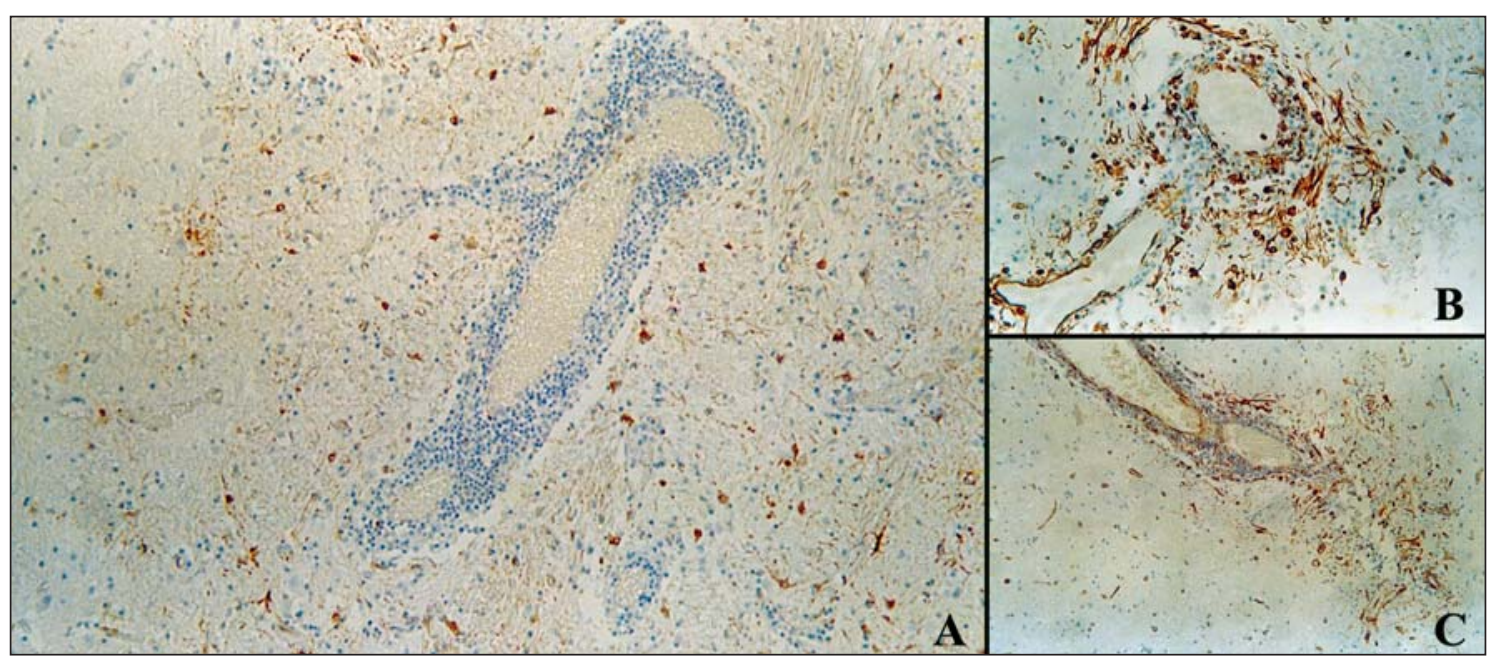

Fig 4. Expressão da GFAP (A) e da VIM (B e C) na região perivascular de vasos com infiltração inflamatória no SNC de cães com cinomose. Obj. $10 x$ (A e C). Obj. $20 x(B)$.

sentaram aumento no volume do citoplasma e na extensão dos prolongamentos celulares, além de coloração mais intensa do citoplasma.

A marcação imunoistoquímica da VIM nos cortes provenientes de animais doentes revelou que as cé- lulas positivas para a proteína estavam presentes em grandes quantidades nas regiões com degeneração e nas proximidades do quarto ventrículo. As regiões sem alterações teciduais visíveis não apresentaram marcação ou a marcação foi escassa. Outros tipos ce- 
lulares, tais como células endoteliais, ependimárias, meníngeas, glia de Bergmann no cerebelo e células monocíticas fagocitárias nos animais que continham infiltração inflamatória, apresentaram-se marcados para a VIM. Da mesma forma que a marcação para a GFAP, a marcação para a VIM foi maior nos animais com cinomose do que nos animais normais (Fig $3 \mathrm{~A}$ e 3B). Nos animais normais, apenas alguns astrócitos apresentaram marcação positiva para a VIM. Tais astrócitos estavam presentes predominantemente na região subependimal e, em comparação aos animais com cinomose, o citoplasma de tais células mostrouse muito menos abundante, assim como a extensão dos seus prolongamentos.

Nas regiões do cerebelo com infiltração inflamatória, especialmente ao redor de manguitos perivasculares com mais de cinco camadas de células inflamatórias, a marcação para a GFAP foi menos intensa do que em outras regiões da substância branca (Fig 4A). Por outro lado, e ao contrário do observado na marcação da GFAP, as regiões próximas a manguitos perivasculares apresentaram células morfologicamente compatíveis com astrócitos marcadas para a VIM, especialmente quando os manguitos continham um número maior de camadas de células inflamatórias. Nestas condições, o citoplasma das células positivas também se mostrou mais volumoso (Fig $4 \mathrm{~B}$ e $4 \mathrm{C}$ ).

A análise estatística das regiões cerebelares ( $R-1$, $R-2$ e R-3) revelou diferença significativa $(p<0,0010)$ entre os animais com cinomose e os animais normais, sendo os valores obtidos, na marcação para a GFAP e para a VIM, menores nos animais normais. Observou-se, ainda nessa análise, diferenças importantes $(p=0,0160)$ entre as regiões $\mathrm{R}-1$ e R-3 em relação à VIM, sendo a marcação para a VIM maior em R-1 do que em R-3 (Tabela 1). Na análise da substância branca do cerebelo quanto à presença ou não de infiltração inflamatória, constatou-se que os animais normais apresentaram menor marcação para a GFAP e para a VIM $(p<0,0001)$ do que os animais doentes, independentemente de, nestes, o tecido apresentar ou não infiltração inflamatória. Na comparação intragrupo (animais doentes com e sem infiltração inflamatória), nenhuma diferença considerada significativa foi

Tabela 1. Expressão da GFAP e da VIM (em $\left.\mu \mathrm{m}^{2}\right)$ avaliada no cerebelo de animais normais e com cinomose.

\begin{tabular}{lccc}
\hline Variável & Animais normais & Animais com cinomose & Geral \\
\hline GFAP & & & \\
R-1 & $5148,21(1222,62)$ & $103690,50(69027,03)$ & $76574,77(94278,63)$ \\
R-2 & $8870,50(13625,38)$ & $90482,20(60431,07)$ & $78130,25(75201,46)$ \\
R-3 & $4856,03(13929,11)$ & $48268,38(61327,67)$ & $39427,80(40492,94)$ \\
Geral & $5148,21(9226,40)^{\mathrm{a}}$ & $80655,27(82310,44)$ & - \\
VIM & & & \\
R-1 & $40,84(140,00)$ & $16770,93(25760,27)$ & $13393,83(26183,99)$ \\
R-2 & $278,21(196,55)$ & $4219,08(10794,27)$ & $2417,41(9677,48)$ \\
R-3 & $108,66(179,95)$ & $1310,75(2187,02)$ & $\left.635,48(2285,71)^{\mathrm{b}}\right)$ \\
Geral & $162,31(247,77)^{\mathrm{a}}$ & $4219,08(16393,60)$ & - \\
\hline
\end{tabular}

Os dados são apresentados na forma de mediana (intervalo interquartil); R-1, substância branca abaixo das folias cerebelares; R2, base das folias, contendo a substância branca e as camadas granular e molecular do cerebelo; R-3, extremidade distal das folias, contendo a substância branca e as camadas granular e molecular do cerebelo; indica diferença, com grau de significância em $p<0,0010$, em relação aos animais com cinomose, independentemente do local mensurado; 'indica diferença, com grau de significância em p=0,0160, em relação ao local $R_{1}$, independentemente do grupo avaliado.

Tabela 2. Expressão da GFAP e da VIM $\left(e m \mu m^{2}\right)$ avaliada na região perivascular da substância branca do cerebelo de animais normais e com cinomose.

\begin{tabular}{lcc}
\hline Variável & Animais normais & Animais com cinomose \\
\hline GFAP & & \\
$\quad$ Ausência de infiltração inflamatória & $4058,24(3692,10)^{\mathrm{a}}$ & $85493,77(104515,71)$ \\
Presença de infiltração inflamatória & - & $86757,39(27583,08)$ \\
VIM & $237,79(342,72)^{\mathrm{a}}$ & $3538,77(7635,34)$ \\
$\quad$ Ausência de infiltração inflamatória & - & $10371,51(43253,03)$ \\
\hline Presença de infiltração inflamatória & & \\
\hline
\end{tabular}

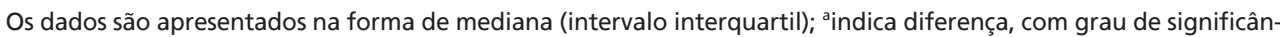
cia em $\mathrm{p}<0,0001$, em relação aos animais com cinomose, independentemente da situação. 
Tabela 3. Expressão da GFAP e da VIM $\left(\mathrm{em} \mu \mathrm{m}^{2}\right)$ avaliada na substância branca do cerebelo de animais normais e com cinomose.

\begin{tabular}{lcc}
\hline Variável & Animais normais & Animais com cinomose \\
\hline GFAP & & \\
$\quad$ Ausência de degeneração & $5148,21(1222,62)^{\mathrm{a}}$ & $76278,91(71222,20)$ \\
Presença de degeneração & - & $57910,53(104425,78)$ \\
VIM & & \\
Ausência de degeneração & $40,84(140,00)^{\mathrm{a}}$ & $9648,34(24637,97)$ \\
Presença de degeneração & - & $58082,18(53449,24)^{\mathrm{b}}$ \\
\hline
\end{tabular}

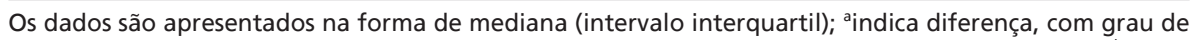
significância em $\mathrm{p}<0,0001$, em relação aos animais com cinomose, independentemente da situação; bindica diferença, com grau de significância em $\mathrm{p}=0,0033$, em relação à situação sem degeneração, intragrupo.

Tabela 4. Expressão da GFAP e da VIM $\left(e m \mu^{2}\right)$ avaliada no tronco encefálico de animais normais e com cinomose.

\begin{tabular}{lccc}
\hline Variável & Animais normais & Animais com cinomose & Geral \\
\hline GFAP & & & \\
r-I & $24888,89(26237,17)$ & $95907,55(97893,38)$ & $48488,43(72968,92)$ \\
r-II & $9960,99(4633,26)$ & $87978,17(43478,54)$ & $59618,21(85219,96)$ \\
Geral & $12557,10(8676,01)^{\mathrm{a}}$ & $95802,90(90214,70)$ & - \\
VIM & & & \\
r-I & $610,92(1052,07)$ & $13047,90(40633,60)$ & $2002,82(17559,37)$ \\
r-II & $47,70(41,59)$ & $2330,32(1774,43)$ & $1741,16(2460,36)$ \\
Geral & $101,60(372,92)^{\mathrm{a}}$ & $2722,37(8627,00)$ & - \\
\hline
\end{tabular}

Os dados são apresentados na forma de mediana (intervalo interquartil); r-l, região do tronco encefálico imediatamente abaixo do epêndima; r-II, região mais ventral do tronco encefálico; ${ }^{a}$ indica diferença, com grau de significância em $p<0,0010$, em relação aos animais com cinomose, independentemente da região mensurada.

observada (Tabela 2). A análise da substância branca do cerebelo quanto à marcação para a GFAP e para a VIM, na presença ou ausência de degeneração tecidual, demonstrou que tal marcação foi significativamente menor $(p<0,0001)$ nos animais normais, independentemente da presença ou não de degeneração nos doentes. Além disso, a marcação para a VIM indicou diferença entre as situações com e sem degeneração - a marcação foi significantemente maior ( $p=0,0033$ ) nas regiões com degeneração (Tabela 3 ). Em relação às regiões selecionadas do tronco encefálico ( $r$-I e r-II), observou-se que a marcação para a GFAP e para a VIM foi significativamente menor $(p<$ o,0010) nos animais normais em comparação aos animais doentes. Nenhuma diferença significativa foi encontrada na análise intragrupo (comparação das regiões r-I e r-II) da marcação para a GFAP e para a VIM no tronco encefálico dos animais com cinomose e dos animais sadios (Tabela 4).

\section{DISCUSSÃO}

Este estudo teve por objetivo avaliar a resposta morfológica e a distribuição dos astrócitos na desmielinização do SNC na cinomose - importante do- ença infecciosa de cães e outros carnívoros ${ }^{4,5}$-cuja desmielinização promovida no SNC se assemelha, em vários aspectos, à desenvolvida em diversas doenças desmielinizantes humanas ${ }^{4,5,8,9}$.

Uma vez que os astrócitos são células que respondem prontamente a ampla variedade de insultos ao tecido nervoso $0^{7,17,18,20,22,23}$ e que correspondem à principal célula infectada pelo $\mathrm{CDV}^{10,13}$, o estudo do comportamento astrocitário nas lesões desmielinizantes do SNC mostra-se importante, especialmente na inferência de possíveis funções dessas células na mediação do processo inflamatório relacionado à desmielinização.

Neste estudo, amostras de cerebelo e de tronco encefálico de animais que vieram a óbito por cinomose foram avaliadas por meio da marcação imunoistoquímica da GFAP e da VIM (proteínas componentes dos filamentos intermediários dos astrócitos, cujo aumento durante os processos de injúria do tecido nervoso sinaliza reatividade astrocitária) ${ }^{16,22,23}$. A escolha do cerebelo e do tronco encefálico baseou-se em informações anteriores de que tais regiões são bastante acometidas por lesões desmielinizantes provocadas pelo $\mathrm{CDV}^{5,14}$. 
É sabido que frente às lesões do SNC ocorre um aumento na expressão astrocitária de GFAP e a VIM, presente nos astrócitos apenas durante os períodos embrionário e pós-natal ${ }^{23,24}$, pode voltar a se expres$\operatorname{sar}^{23}$. O aumento na expressão da GFAP e a reexpressão da VIM, seguidos à injúria, foram relatados nos experimentos de Bondan et al. ${ }^{25}$ e Sanchez et al. ${ }^{28}$ nas regiões adjacentes às lesões desmielinizantes promovidas no tronco encefálico de ratos Wistar. O aumento da GFAP também foi referido por Headley et al. ${ }^{26} \mathrm{em}$ cães com cinomose e por Lemos e Alessi ${ }^{27}$ em cavalos com leucoencefalomalácea (LEM), que constataram inclusive um aumento na expressão de GFAP em regiões sem alterações visíveis nos animais doentes, sugerindo a participação astrocitária na patogenia da LEM.

No presente trabalho, o aumento da expressão da GFAP e a reexpressão da VIM em células morfologicamente compatíveis com astrócitos foram observados não apenas nos sítios imediatos às lesões degenerativas, mas também em diferentes locais por toda a extensão do tecido. Observou-se também que a imunorreatividade das proteínas astrocitárias nas três regiões cerebelares ( $R-1, R-2$ e $R-3$ ) foi maior nos animais com cinomose do que nos animais normais, especialmente em R-1. Tal resultado foi compatível com o obtido na marcação imunoistoquímica da GFAP no cerebelo de cães com cinomose por Headley et al. ${ }^{26}$, que notaram diferenças significativas entre as três regiões, sendo a marcação maior em R-1 e menor em R-2 e R-3, respectivamente.

Uma vez que R-1 corresponde apenas à substância branca do cerebelo e que a mesma é tida como um local importante de replicação viral e de desmielinização na cinomose $e^{5,14}$, conclui-se que o aumento da reatividade astrocitária demonstrado nesta região acompanha o processo desmielinizante do SNC pelo vírus. Essa constatação na referida doença pode ser embasada pela observação feita, nos animais doentes, de que regiões da substância branca com áreas de degeneração, compatíveis com desmielinização, apresentaram marcação significantemente superior para a VIM do que as áreas sem degeneração. Além disso, a marcação da GFAP e da VIM na substância branca do tronco encefálico foi maior nos animais com cinomose do que nos animais normais.

Com base na descrição de que citocinas (tais como o IFN- $\gamma$ e o TNF- $\alpha$ ), potencialmente deletérias à mielina ou aos oligodendrócitos, são liberadas por astrócitos $^{21}$, a reatividade astrocitária (observada neste estudo pelo aumento na expressão das fibrilas gliais) pode estar relacionada ao desencadeamento do processo de desmielinização. Assim, no caso da cinomose canina, a infecção do SNC, ou apenas dos próprios astrócitos, pelo CDV poderia ativar funções inflamatórias astrocitárias, que causariam a desmielinização do SNC como efeito secundário à tentativa de combate ao vírus por essas células.

Neste estudo, a análise das regiões subependimárias e mais ventrais do tronco encefálico e a análise da substância branca do cerebelo (nas condições de presença e ausência de infiltração inflamatória perivascular) dos animais com cinomose também foram realizadas. Observou-se que a marcação da GFAP e da VIM foi maior nas regiões subpendimárias do tronco encefálico e que a marcação da VIM na região perivascular do cerebelo foi mais evidente quando o infiltrado era maior (com maior número de camadas de células inflamatórias). Apesar de nenhuma diferença estatisticamente significante ter sido obtida para os resultados acima mencionados - o que pode ser devido à alta variabilidade de resultados encontrados nas amostras -, tal observação permite uma especulação a respeito da reatividade astrocitária frente à infecção do SNC pelo CDV ou ainda sobre a sua ação no processo inflamatório do tecido nervoso.

Alguns autores relatam em seus experimentos a possibilidade de o CDV se dispersar por meio do líquor $^{3,4,11,14}$. O aumento da reatividade astrocitária, bem como o da degeneração tecidual, nas regiões subependimárias (que apresentam contato com o líquor) poderia indicar uma relação entre a presença do vírus, a ação astrocitária e a desmielinização dessa região. Além disso, sabe-se que o CDV é um vírus que se dissemina pelo sangue $\mathrm{e}^{4,5}$ e que a penetração de células inflamatórias no SNC também se dá pela circulação sangüínea ${ }^{5,7,13}$. Uma vez que os astrócitos desempenham diferentes funções de proteção do tecido nervoso ${ }^{16,17,18}$, o aumento da reatividade astrocitária perivascular poderia estar relacionado à função de proteção do SNC por essas células (mediando o processo inflamatório) ou à ativação dessas células pelo próprio vírus ou mesmo por elementos do sistema imunológico. A comunicação entre os elementos do sistema imunológico e os astrócitos é sugerida por alguns autores como mediadora dos processos inflamatórios ${ }^{20,21}$ e poderia estar relacionada também à desmielinização.

Uma vez que os astrócitos possuem a habilidade de liberar mediadores pró-inflamatórios ${ }^{16,17,18,21}$, a ação deste tipo celular no desencadeamento de uma reação inflamatória seguida à infecção do SNC pelo CDV, com conseqüente desmielinização do tecido nervoso, pode ser sugerida. Por outro lado, ações antiinflamatórias também são descritas em astrócitos ${ }^{15,21}$. Assim, 
da mesma forma que a micróglia, os astrócitos poderiam exercer funções mediadoras da resposta inflamatória antiviral, realizando fagocitose e liberando citocinas pró-inflamatórias, tais como o TNF- $\alpha$ e o IFN- $\gamma$, que promovem como efeito indireto a destruição das bainhas de mielina ${ }^{10,16}$, assim como liberando mediadores antiinflamatórios (TGF- $\beta$, por exemplo) como mecanismo de contra-regulação inflamatória, na tentativa de promover o retorno à homeostasia ${ }^{15}$.

Com base na acentuada diferença encontrada na imunorreatividade astrocitária entre os animais doentes e os normais, independentemente de se definir qual a função exata do aumento da reatividade astrocitária nas lesões desmielinizantes, é possível concluir que a resposta astrocitária participa ou está envolvida com as lesões desmielinizantes induzidas pelo vírus da cinomose no SNC.

\section{REFERÊNCIAS}

1. Bondan EF, Lallo MA. Mielinização, desmielinização e remielinização no sistema nervoso central (SNC)-parte I. Aspectos histofisiológicos relevantes à formação e à integridade da mielina central. Rev Inst Ciênc Saúde 1998;16:103-111.

2. Raine CS. The neuropathology of myelin diseases. In Morell P (Ed). Myelin. 2.Ed. New York: Plenum Press, 1989:259-310.

3. Mitchell WJ, Summers BA, Appel MJG. Viral expression in experimental canine distemper demyelinating encephalitis. J Comp Pathol 1991;104:77-87.

4. Summers BA, Greisen HA, Appel MJ. Early events in canine distemper demyelinating encephalomyelitis. Acta Neuropathol 1979;46:1-10.

5. Vandevelde M, Zurbriggen A. Demyelination in canine distemper virus infection: a review. Acta Neuropathol 2005;109:56-68.

6. Zurbriggen A, Schmid I, Graber HU, Vandevelde M. Oligodendroglial pathology in canine distemper. Acta Neuropathol 1998;95:71-77.

7. Vandevelde M, Bichsel P, Cerruti-Sola S, Steck A, Kristensen F, Higgins RJ. Glial proteins in canine distemper virus-induced demyelination. Acta Neuropathol 1983;59:269-276.

8. Botteron C, Zurbriggen A, Griot C, Vandevelde M. Canine distempervirus-immune complexes induce bystander degeneration of oligodendrocytes. Acta Neuropathol 1992; 83:402-407.

9. Obeid EO, Partidos CD, Howard CR, Steward MW. Protection against morbillivirus-induced encephalitis by immunization with rationally designed synthetic peptide vaccine containing B and T cell epitopes from de fusion protein of measles virus. J Virol 1995;69:1420-1428.
10. Zurbriggen A, Vandevelde M, Dumas M. Secondary degeneration of oligodendrocytes in canine distemper vírus infection in vitro. Lab Invest 1986;54:424-431.

11. Higgins RJ, Krakowka SG, Metzler AE, Koestner A. Experimental canine distemper encephalomyelitis in neonatal gnotobiotic dogs. Acta Neuropathol 1982;57:287-295

12. Vilafranca M, Tello M, Pumarola M, Domingo M. Neural cells from dogs with spontaneous distemper encephalitis express class II major histocompatibility complex molecules. J Comp Pathol 1996;114:43-50.

13. Wunschmann A, Kremmer E, Baumgartner W. Phenotypical characterization of $\mathrm{T}$ and $\mathrm{B}$ cell areas in lymphoid tissues of dogs with spontaneous distemper. Vet Immunol Immunopathol 2000;73:83-98.

14. Alldinger S, Baumgartner W, Orvell C. Restricted expression of viral surface proteins in canine distemper encephalitis. Acta Neuropathol 1993; 85: 635-645.

15. Aloisi F. Immune function of microglia. Glia 2001;36:165-179.

16. Benveniste EN. Cytokines: influence on glial cell gene expression and function. In Blalock JE (ed). Neuroimmunoendocrinology. 2.Ed. Basel: Karger, 1992:106-153.

17. Dong Y, Benveniste EN. Immune function of astrocytes. Glia 2001;36:180-190.

18. Montgomery DL. Astrocytes: form, functions, and roles in disease. Vet Pathol 1994;31:145-167.

19. Shimada A, Uemura T, Yamamura Y, Koima S, Morita T, Umemura T. Localization of metallothionein-I and II in hypertrophic astrocytes in brain lesions of dogs. J Vet Med Sci 1998;60:351-358.

20. Bradl M. Immune control of the brain. Springer Semin Immunopathol 1996;18:35-49.

21. Selmaj K. Pathophysiology of the blood-brain barrier. Springer Semin Immunopathol 1996;18:57-73.

22. Pekny M, Johansson CB, Eliasson C, et al. Abnormal reaction to centra nervous system injury in mice lacking glial fibrillary acidic protein and vimentin. J Cell Biol 1999;145:503-514.

23. Takamiya Y, Kohsaka S, Toya S, Otani M, Tsukuda Y. Immuno-histochemical studies on the proliferation of reactive astrocytes and the expression of cytoskeletal proteins following brain injury. Dev Brain Res 1988;38:201-210.

24. Pixley SK, de Vellis J. Transition between radial glia and mature astrocytes studied with a monoclonal antibody to vimentin. Dev Brain Res 1984;15:201-209.

25. Bondan EF, Lallo MA, Dagli MLZ, Sanchez M, Graça DL. Estudo da imunorreatividade astrocitária para GFAP e vimentina no tronco encefálico de ratos Wistar submetidos ao modelo gliotóxico do brometo de etídio. Arq Neuropsiquiatr 2003;61:642-649.

26. Headley SA, Soares IC, Graça DL. Glial fibrillary acidic protein (GFAP) immunoreactive astrocytes in dogs infected with canine distemper virus. J Comp Pathol 2001;125:90-97.

27. Lemos KR, Alessi AC. Astrócitos imunorreativos à proteína glial fibrilar ácida (GFAP) em sistema nervoso central de equinos normais e de eqüinos com leucoencefalomalácia. Pesq Vet Brás 1999;19:104-108.

28. Sanchez M, Bondan EF, Lallo MA, et al. Immunohistochemical staining of the macrophagic and astrocytic response in the brainstem of Wistar rats submitted to the ethidium bromide gliotoxic model and treated with cyclophosphamide. Arq Neuropsiquiatr 2006;64:787-793. 